\title{
Omental transposition in chronic spinal cord injury
}

\author{
GL Clifton ${ }^{1}$, WH Donovan ${ }^{2,7}, \mathrm{MM}$ Dimitrijevic ${ }^{6}, \mathrm{SJ} \mathrm{Allen}^{3}, \mathrm{~A} \mathrm{Ku}^{4}, \mathrm{JR}$ Potts III ${ }^{5}$, FG Moody ${ }^{5}$, C Boake ${ }^{2,7}$, \\ AM Sherwood ${ }^{6}$ and JV Edwards \\ Departments of ${ }^{1}$ Neurosurgery, ${ }^{2}$ Physical Medicine and Rehabilitation, ${ }^{3}$ Anesthesia, ${ }^{4}$ Radiology, ${ }^{5}$ Surgery, University \\ of Texas-Houston Medical School; ${ }^{6}$ Division of Restorative Neurology, Baylor College of Medicine; ${ }^{7}$ The Institute for \\ Rehabilitation and Research
}

\begin{abstract}
The results of omental transposition in chronic spinal cord injury have been reported in 160 patients operated upon in the United States, Great Britain, China, Japan, India and Mexico, with detailed outcomes reported in few studies. Recovery of function to a greater degree than expected by natural history has been reported. In this series, 15 patients with chronic traumatic spinal cord injury ( $>1.5$ years from injury) underwent transposition of pedicled omentum to the area of spinal cord injury. Of the first series of four patients who were operated upon in 1988, one died, one was lost to follow-up and two were followed with sequential neurological examinations and Magnetic Resonance Imaging (MRI) scans preoperatively, at 1 year post injury and $4 \frac{1}{2}$ years post injury. Another 11 patients were operated in 1992 and underwent detailed neurological and neurophysiological examinations and had MRI scans preoperatively and every 4 months for at least 1 year after surgery. All patients completed a detailed self-report form. Of the total of 13 operated patients in both series followed for $1-4 \frac{1}{2}$ years, six reported some enhanced function at 1 year and five of these felt the changes justified surgery primarily because of improved truncal control and decreased spasticity. MRI scans showed enlargement of the spinal cord as compared to preoperative scans in seven patients. Increased T2 signal intensity of the spinal cord was found by 1 year after surgery in eight of 13 operated patients. Neurophysiological examinations of 11 patients in the second series agreed with self-reports of increases or decreases in spasticity $(r=0.65, P<0.03)$. Somatosensory evoked potentials and motor evoked potentials at 4 month intervals up to 1 year in these patients showed no change after surgery. Neurological testing, using the American Spinal Injury Association (ASIA) and International Medical Society of Paraplegia (IMSOP) international scoring standards, failed to show any significant changes when the 1-year post operative examination was compared to the first preoperative examination except for decreased sensory function after surgery which approached statistical significance. When the 11 patients in the second series were compared to eight non-operated matched patients, followed for a similar length of time, no significant differences were found. Complications encountered in the operated patients from both series included one postoperative death from a pulmonary embolus, one postoperative pneumonia, three chronic subcutaneous cerebrospinal fluid (CSF) fistulae requiring wound revision, and one patient who developed biceps and wrist extensor weakness bilaterally requiring graft removal. We conclude that the omental graft remains viable over time and this operation can induce anatomical changes in the spinal cord as judged by MRI. Some patients reported subjective improvement but this was not supported by objective testing. We, therefore, find no justification for further clinical trials of this procedure in patients who have complete or sensory incomplete lesions. Further testing in motor incomplete patients would seem appropriate only with compelling supportive data.
\end{abstract}

Keywords: spinal cord injury; omental transposition; MRI; neurophysiology; neurological examinations; neurological standards

Correspondence: GL Clifton, Professor and Chairman, Department of Neurosurgery, The University of Texas Houston Health Science Center, 6431 Fannin, Suite 7.149, Houston, TX 77030, USA

\section{Introduction}

The concept of omental transposition to brain and spinal cord was first proposed by Goldsmith. ${ }^{1}$ The rationale is based upon the omentum's unusual biochemical properties. Omentum has been shown to 
contain high levels of neurotransmitters and to contain a lipid-soluble angiogenic factor which induces growth of new blood vessels. ${ }^{2,3,4,5}$ A lipid-soluble factor which induces neurite outgrowth in cultured neurons has been reported in omental extracts. ${ }^{6}$ Omentum has been shown to enhance neurite outgrowth across a collagen bridge after experimental spinal cord transection. ${ }^{7}$

Goldsmith's work and that of others established in animals that pedicled omentum, subcutaneously tunneled from the abdomen and placed against the brain or spinal cord, developed vascular communications from omentum to neural tissue. ${ }^{1,8-10}$ There is evidence that the blood flow provided to the brain by pedicled omentum experimentally is sufficient to prevent infarction after middle cerebral artery occlusion. ${ }^{11-17}$ Vascular communications of omental graft to the brain have been shown angiographically in children with Moya-Moya disease who underwent omental transposition. ${ }^{18}$ There are many reports of omental transposition to the brain of patients after stroke. ${ }^{19-26}$

There are eight clinical reports of over 160 patients undergoing omental transposition after spinal cord injury. 1,27-33 Few or no details of the neurological outcome are given in most of this literature, but substantial recovery of function is reported in most of it. Omental transposition is being widely performed throughout the world and has recently been performed in 40 patients in the United States. ${ }^{1}$ Goldsmith has stated that $40 \%$ of the spinal cord injured patients undergoing omental transposition have shown "varying degrees of neurological improvement'. 'Systematic follow-up using anatomical, neurophysiological and neurological measures has not been reported in any series. In this study, we report a series of two groups of patients with chronic spinal cord injury who underwent omental transposition with frequent multimodality follow-up measures to determine if the procedure could offer benefit.

\section{Material and methods}

\section{First series}

In 1989 a pilot series of four patients with tetraplegia underwent omental transposition at The Hunter Holmes McGuire Veterans Administration Hospital, Richmond, Virginia. The research procedures were approved by The Committee for The Protection of Human Subjects of the Medical College of Virginia,
Richmond, Virginia. One patient was Level C5, ASIA Impairment Scale (AIS) A, with a zone of partial preservation (ZPP) to Level L5 (no sacral sensation) and three were levels $\mathrm{C} 6, \mathrm{C} 5$, and $\mathrm{C} 5$, all AIS C. ${ }^{34}$ Patients had been injured $1 \frac{1 / 2}{2}$ years (one), 2 years and 9 months (two), and 3 years (one) prior to undergoing omental transposition. One patient (AIS A) was lost to follow-up 1 year after surgery after reporting no improvement and a second (AIS C) died of a pulmonary embolus in the postoperative period. Two patients (AIS C), therefore, underwent long term follow-up. Patients were given standard neurological examinations using the examination developed by the National Acute Spinal Cord Injury Study (NASCIS). ${ }^{35}$ One author (GLC) performed all examinations, assisted by a physical therapist. Patients underwent neurological examination on two different occasions, 2 months apart prior to surgery and then at 4, 8, 12 and 20 months, and at 4 years and 6 months after surgery. Somatosensory evoked potentials were done preoperatively and 1 year post surgery. MRI scans of the cervical spine were done prior to surgery, 1 year after surgery, and $4 \frac{1}{2}$ years after surgery.

\section{Second series}

A second larger series of 11 patients underwent omental transposition between April 12, 1992, and December 8, 1992, at the Hermann Hospital, Houston, Texas, with more outcome measures at more frequent intervals than were used in the first series. These patients underwent detailed assessment twice at 2 month intervals before surgery and at 4 month intervals for 1 year after surgery. A comparable group of eight patients who did not have surgery were examined 1 year apart for comparison purposes.

Of the nine male and two female patients undergoing surgery, eight were tetraplegic and three were paraplegic. The average time since injury was 53.3 months (range $21-156$ ). All by their history, had been neurologically stable for at least 1 year. The mean age was 32 years (range 14-50). By the American Spinal Injury Association (ASIA) Classification System, four were AIS A, with a zone of partial preservation that averaged 19 levels below the neurologic level of lesion (range 15-22 levels), six were AIS B and one was AIS C. Seven patients had previously undergone surgery for stabilization at the time of injury and four had been managed non-operatively. The eight patients who met the inclusion criteria for the study but declined the operation were followed for 1 year (Table 1).

Table 1 Patient biographical data

\begin{tabular}{|c|c|c|}
\hline \multicolumn{2}{|l|}{ Operated group } & Non-operated group \\
\hline $\bar{\chi}=32$ years $(r=14-50)$ & Age & $\overline{\bar{\chi}}=28.3$ years $(r=19-50)$ \\
\hline 9 males 2 females & Sex & 5 males 3 females \\
\hline Cervical 8 Thoracic 3 & Level & Cervical 8 Thoracic 0 \\
\hline A4 B6 C1 & ASIA imp scale & $\mathrm{A} 1 \quad \mathrm{~B} 5 \quad \mathrm{C} 2$ \\
\hline $\bar{\chi}=55.3$ months $(r=21-156)$ & Time since injury & $\bar{\chi}=81.6$ months $(r=22-202)$ \\
\hline
\end{tabular}


The research procedures were approved by The Committees for the Protection of Human Subjects of The Universtiy of Texas-Houston Health Science Center, of The Institute for Rehabilitation and Research (TIRR), and of Baylor College of Medicine. All patients had adequate measured pulmonary function and had incomplete spinal cord injuries or complete injuries with zones of partial preservation well below their lesion. Trauma was the etiology of all cases in both groups. The following assessments were performed:

(a) Self assessment questionnaires: One year after omental transposition the surgical group completed a questionnaire and was then interviewed regarding its responses. The questionnaire asked for estimates of change in spasticity, sensory function, motor function, truncal control, bowel and bladder function at 4, 8 and 12 months after surgery;

(b) Neurological examinations: Standard examinations performed according to the ASIA International Standards for Neurological and Functional Classification of Spinal Cord Injury ${ }^{34}$ were used for scoring of motor function in the upper and lower extremities and sensory function in all dermatomes for pin prick and light touch. The NASCIS examinations were used for sensory scoring of proprioception and deep pain. ${ }^{35}$ These instruments allowed for classification and scoring of spinal cord injuries. Examinations were performed by one author (WHD) at 2 times, 2 months apart, prior to surgery, and then at 4,8 and 12 months after surgery on the 11 patients who underwent omental transposition. The second group of eight patients who were eligible for but declined surgery were also examined 12 months apart for comparison purposes. The only exceptions were that one operated patient's baseline exams were 11 months apart, one operated patient missed the 12 month follow-up exam but was tested 24 months after surgery, and one nonoperated patient's exams were 23 months apart (Table 2);

(c) Magnetic Resonance Imaging (MRI): Baseline MRI's through the area of injury were performed within 1 month prior to surgery for four patients.

Table 2 Examination times

\begin{tabular}{lccc}
\hline & Baseline 1 & Baseline 2 & 1 year \\
\hline Operated $(n=11)$ & $\mathrm{A}$ & $\mathrm{B}$ & $\mathrm{C}$ \\
Non-operated $(n=8)$ & $\mathrm{D}$ & & $\mathrm{E}$ \\
\hline
\end{tabular}

Patients were examined at the time intervals shown. Correlations between $\mathrm{B}$ and $\mathrm{A}$ and $\mathrm{E}$ and $\mathrm{D}$ were used to test intrarater reliability. The change scores between $C$ and A when compared to those between $\mathrm{E}$ and $\mathrm{D}$ were used to evaluate the effect of surgery
Seven other patients had immediate post operative MRI's after metal fixation devices were removed at surgery. MRI's with and without contrast were then performed using the same technique as the initial scans at 4,8 and 12 months after surgery. The two patients followed up to 2 years had MRI's at 2 years after surgery. MRI's were independently interpreted and coded by one neuroradiologist (AK).

The following assessments of MRI scans in the 11 operated patients in the second series were made: contact of omentum with spinal cord, size of spinal cord, intensity of spinal cord T2 signal, extent of spinal cord T2 signal (measured in number of vertebral bodies), spinal cord shape, spinal cord enhancement, presence of cyst, size of cyst and enhancement of omentum. Atrophy or increase in size of the spinal cord was judged by a measured decrease in size of the spinal cord at the level of injury compared to the levels above and below. Changes in these variables relative to prior scans were assessed at each interval;

(d) Neurophysiological Assessment: Patients underwent detailed neurophysiological assessment (MMD) including: (1) cervical and lumbosacral somatosensory evoked potentials, (2) motor evoked potentials, and (3) brain motor control assessment (BMCA) for evaluation of spasticity and motor control (a surface electrode, poly-EMG technique). The 11 surgical patients had one (seven patients) or two (four patients) preoperative examinations and then repeat assessments at 4, 8 and 12 months after surgery. Both cervical and lumbosacral somatosensory evoked potentials were measured. ${ }^{36,37}$ For lumbosacral somatosensory evoked potentials, $\mathrm{R}$ waves, $\mathrm{S}$ waves and P30 potentials were recorded. Motor evoked potentials were measured for both upper and lower limbs using transcranial magnetic motor cortex stimulation by methods previously described. ${ }^{38}$ Spasticity was assessed using BMCA of upper and lower limbs. ${ }^{39,40}$ This technique measures EMG activity in response to voluntary and passive movement. Lower limb BMCA has a well-developed quantification process whereas there is no scheme for quantification of upper limb responses; $;^{39,40}$

(e) Statistics: Intraobserver reliability of ASIA scores was evaluated in the 11 surgical patients who were examined twice, 2 months apart, prior to surgery, and in eight non-operated patients examined twice, 1 year apart. Intrarater reliability for each pair of exams was estimated using intraclass correlation. ${ }^{41}$ Changes in spasticity of the lower limbs over the period from before surgery to 1 year later were assessed by patient self reports and by BMCA. These were then correlated.

The stability of the neurophysiological recordings has been previously documented in related 
studies ${ }^{42}$ which showed an overall reliability index of 0.92 , which is in agreement with previous published figures indicating a repeatability of $5 \%$ for surface EMG recordings. ${ }^{43}$ The consistency of these findings was further documented through repeated recordings 1-2 months apart prior to surgery in four patients, and in repeated recordings in non-operated subjects 6 months to 1 year apart, all of whom had consistent patterns of responses to the protocol, with overall quantitative changes ranging from $3 \%$ to $18 \%$, with one exception (49\% change, accompanied by a self reported diminished spasticity on the second baseline recording);

(f) Surgical Procedure: The abdominal portion of the operation, all performed by two surgeons (FGM and JRP), was conducted by first performing a laparotomy as described by Goldsmith. ${ }^{21}$ In four patients in the first series and in five patients in the second series (two tetraplegics and three paraplegics) the omentum was pedicled by dividing its vascular supply so that the right gastroepiploic artery and vein provided supply and the omentum could be lengthened to at least $45 \mathrm{~cm}$. Once pedicled, the graft was tunneled subcutaneously to the neck or lateral chest wall. The patient was then placed in a prone position and either a thoracic or a cervical laminectomy was performed depending upon the level of lesion (performed by GLC). The graft was then tunneled subcutaneously to the incision. The dura and arachnoid were opened and the graft applied to the spinal cord at the area of injury plus several centimeters above and below it. The graft was then sutured to the opened dura. Viability of grafts were assessed by doppler of the vascular pedicles and also by inspection. Avascular segments of omentum turn a dusky blue color. Only vascularized omental tissue was grafted. In six tetraplegics, free omental grafts were taken rather than creating a pedicle for blood supply. The right gastroepiploic artery and vein were then sutured to the external carotid artery and internal jugular vein respectively through a left cervical incision (performed by GLC). The graft was tunneled posteriorly and the patient then turned prone for cervical laminectomy. The graft was then applied and closure was performed in the same way as for pedicled grafts. All wire and metal fixation, if any, were removed at laminectomy.

\section{Results}

First series

Two of the four patients operated in the first series underwent MRI preoperatively, 1 year postoperatively, and $4 \frac{1}{2}$ years postoperatively. The neurologic exam- inations were performed by the operating surgeon (GLC) and do not have the force of those in the second series. The MRI data is unique because of the length of follow-up. These two patients, followed up to $4 \frac{1}{2}$ years after surgery are discussed.

A 48 year old male sustained a C5 AIS C spinal cord injury from a fall without bone injury, 3 years prior to omental transposition. He had slight motor improvement for the first 12 months after injury and then neurologically plateaued with intermittent trace quadriceps and gastrocnemius on the left and intermittent trace hamstrings and toe flexion, bilaterally. He had Grade 4 biceps bilaterally but no other motor function below C5 except the trace movements noted. He also had only patchy sensory function below $\mathrm{C} 5$, including the sacral segments. By 25 months and 54 months after surgery he had gained Grade 1-2 iliopsoas, quadriceps and toe flexion with grade $2-3$ gastrocnemius bilaterally. Functionally this patient was unimproved. Somatosensory evoked potentials were unchanged from preoperative study. This patient's MRI's done preoperatively, at 1 year and at $4 \frac{1}{2}$ years are shown in Figure 1. Preoperatively, sagittal $\mathrm{T} 1$ and $\mathrm{T} 2$ weighted images were consistent with focal gliosis at C3 (Figure 1a, b). One year after surgery, the spinal cord deviated into the laminectomy defect with the fat of the omentum apposing it. On T2 weighted images, the spinal cord was bright in the area under the omental attachment (Figure 1c, d). On Tl weighted images, the spinal cord was unchanged. On T2, 4 $1 / 2$ years after surgery, there was no fat overlying the spinal cord. The area dorsal to the spinal cord where fat lay 1 year after surgery was occupied by CSF as seen on T1 and T2 weighted image (Figures 1e, f). The spinal cord was more atrophic than at 1 year after surgery.

A 41 year old male, C5 AIS C, was injured in a motor vehicle accident 2 years and 9 months prior to omental transposition. He underwent a C3-4 diskectomy and fusion acutely after injury and was sensory incomplete and motor complete below $\mathrm{C} 5$ in the period immediately after injury. Before omental transposition, he had Grade 5 biceps and deltoid bilaterally and consistent trace toe flexion on the right and intermittent toe flexion on the left. He had impaired touch sensation in all dermatomes below T1 bilaterally with intact pinprick from T1-T6 only and no pinprick sensation below T6. By 18 months after surgery he had gained Grade 2-3 quadriceps, iliopsoas, and toe flexion bilaterally as well as Grade 2 triceps bilaterally. Sensation to light touch improved below T6. These neurological findings were unchanged at 54 months after surgery. This patient reported improved truncal control, decreased spasticity, increased sensation beginning at 8 months after surgery and maximal at 2 years after surgery. Somatosensory evoked potentials were unchanged. His MRI scans are shown in Figure 2. The patient's preoperative MRI was consistent with focal myelomalacia and gliosis at C3-4 (Figures 2a, b). One year after surgery, the spinal 
cord was deviated into the laminectomy defect with the omental fat apposing the dorsal surface (Figures $2 c, d)$. There was some increase in apparent size of the spinal cord. On T2 weighted images, the spinal cord beneath the area of transposition showed very bright signal intensity. There were no definite changes between the 1 year postoperative MRI and the scan done $4 \frac{1}{2}$ years after surgery (Figures $2 \mathrm{e}, \mathrm{f}$ ). Fat was still detected abutting the spinal cord.

\section{Second series}

Based on the outcomes from the first series, 11 more SCI patients were offered omental transposition.

\section{Self assessment questionnaires}

Of the 11 patients, five reported that spasticity was not a major problem preoperatively. In three it did not change postoperatively while two reported increase in spasticity. Three of six patients in whom spasticity was a major problem preoperatively, reported a significant decrease in spasticity beginning at 4-8 months after surgery and plateauing by 12 months. Six of the 11 also, reported improved truncal control beginning at 4-8 months after surgery.

Slight improvement in all the sensations of touch, pain, heat and cold below the level of injury was reported by four patients at $4-8$ months after surgery. One patient reported a decrease in the sensation of touch. There were no consistent reports of changes in bowel and bladder sensation or function.

Subjective improvement in the function of specific muscle groups was reported by five patients in their arms and by three patients in their legs beginning at about 8 months after surgery. One patient, a C6 sensory incomplete tetraplegic, noted decrease in bilaterial biceps and wrist extensor function 4 months after surgery. This patient is discussed under Complications.

\section{Neurological examinations}

\section{Rater Reliability}

The rater reliability of the neurological scores was evaluated between the two pre-surgery baseline exams of the operated patients and between the two exams of the non-operated patients. At each examination, the same physician (WHD) rated the ASIA scores and the two elements of the NASCIS-2 sensory scores without reviewing the patient's previous examinations (Table 2). Intrarater reliability between examinations was estimated using the intraclass correlation coefficient (ICC). ${ }^{41}$ Reliability between baseline scores was tested by comparing $\mathrm{B}$ to $\mathrm{A}$ and between baseline and 1 year follow-up in the non-operated group by comparing $\mathrm{E}$ to $\mathrm{D}$. The effect of surgery was evaluated by comparing the change scores between $\mathrm{C}$ to $\mathrm{A}$ and $\mathrm{E}$ to $\mathrm{D}$.

Table 3 presents intraclass correlations measuring intrarater reliability between the two examinations for each patient group. The ASIA motor score was almost perfectly reliable, and the ASIA sensory and NASCIS2 proprioception scores were acceptably reliable at both intervals. The NASCIS-2 deep pain score appeared less reliable especially over 1 year. These data indicated that the neurological scoring system chosen was mostly reliable and would therefore be sensitive to changes produced by treatment.

\section{Effect of surgery}

The statistical procedures used to evaluate the effect of treatment in this study are the same as those used in the NASCIS-2 study. ${ }^{35}$ First, change scores were calculated between the neurological scores at the baseline examination and 1 year follow-up examination (change score $=1$ year score minus baseline score). The first of the two baseline examinations was used in calculating the change score. Second, the effect of surgery was evaluated by comparing the mean change scores between the operated and non-operated patients, using independent-groups $t$ tests. This form of analysis is mathematically equivalent to that used by Bracken et $a l .{ }^{35}$ One operated patient did not have a 1 year followup examination and the neurological scores from his 2 year follow-up examination were substituted. For the operated patients, the mean time from the baseline examination to surgery was 2.4 months (range $0.3-4.5$ ) and the mean time from surgery to the follow-up examination was 13.5 months (range $10.9-24$ ). For the non-operated patients, the mean time between the two examinations was 14.9 months (range 12.2-23).

Table 4 presents the mean changes in the neurological scores of the operated and non-operated patients, together with the significance levels of the between-group $t$ tests. None of these comparisons

Table 3 Rater reliability of neurological scores

\begin{tabular}{lcc}
\hline Score & $\begin{array}{c}\text { Operated group: } \\
\text { Two baseline exams }\end{array}$ & $\begin{array}{c}\text { Non-operated group: } \\
\text { Baseline exam to } \\
\text { 1-year follow-up }(\mathrm{n}=8)\end{array}$ \\
\hline months apart (n=11) & $r$ \\
ASIA motor & $r$ & 0.99 \\
ASIA pinprick & 0.98 & 0.84 \\
ASIA light touch & 0.83 & 0.80 \\
NASCIS-2 proprioception & 0.76 & 0.83 \\
NASCIS-2 deep pain & 0.91 & 0.61 \\
\hline
\end{tabular}


showed any evidence for improved neurological functioning in the operated patients. In contrast, there was a decrease in the mean ASIA Light Touch score in the operated patients, but not in the nonoperated patients, and the comparison between these mean change scores fell just short of the statistical significance level $(P<0.05)$.

To rule out the possibility that the standard neurological scores were insensitive to small changes that might have occurred only at the level of each patient's spinal cord lesion, the effect of surgery was also evaluated using change scores for the neurological level of injury and for three segments below it. The arm motor, the pinprick, and the light touch change scores were compared between operated and nonoperated patients, using the same statistical procedures used with the total neurological scores. Again, none of the between-group differences were statistically significant $(P>0.40$, two-tailed $)$.
Thus in this second series of omental transpositions, there were no overall improvements in ASIA scores and in fact there were slight worsenings which did not reach the level of significance when the operated and non-operated groups were compared collectively to themselves and to each other over time. Nonetheless, objective improvements and worsenings were recorded for certain individuals within both groups. Table 5 lists the changes between the 12 month and baseline examinations for 6 neurologic parameters for all patients. Patient Number 8 in the operated group had marked motor and sensory losses, patient Number 10 had notable sensory losses as did Number 11 on one side. At the same time patient Number 6 had clear sensory gains. The same comparisons can be made between Nos. 3 and 8 versus Nos. 4 and 7 in the nonoperated group. Table 6 lists a summation of the patient surveys described earlier and compares the patients' perceptions from their self reports with the

Table 4 Mean change in neurological scores in operated and non-operated patients from the baseline examination to the 1year follow-up examination

\begin{tabular}{lccc}
\hline Score & $\begin{array}{c}\text { Operated } \\
\text { patients }(\mathrm{n}=11)\end{array}$ & $\begin{array}{c}\text { Unoperated } \\
\text { patients }(\mathrm{n}=8)\end{array}$ & $\mathrm{P}$ \\
\hline ASIA motor & $-0.64 \pm 3.30$ & $-0.38 \pm 1.06$ & 0.832 \\
ASIA pinprick & $-2.18 \pm 11.92$ & $0.13 \pm 7.04$ & 0.632 \\
ASIA light touch & $-11.55 \pm 13.10$ & $0.75 \pm 10.44$ & 0.071 \\
NASCIS-2 proprioception & $0.91 \pm 3.11$ & $0.50 \pm 4.87$ & 0.826 \\
NASCIS-2 deep pain & $-1.00 \pm 2.61$ & $-0.13 \pm 4.64$ & 0.606 \\
\hline
\end{tabular}

Table 5 Changes in neurological exams at 1 year in operated and non-operated patients

\begin{tabular}{|c|c|c|c|c|c|c|c|c|c|c|c|c|c|}
\hline \multirow{2}{*}{$\begin{array}{l}\text { Operated } \\
\text { patients }\end{array}$} & \multirow{2}{*}{$\begin{array}{c}\text { Level } \\
\text { AIS }\end{array}$} & \multicolumn{2}{|c|}{$\begin{array}{l}\text { Motor } \\
\text { (arm) }\end{array}$} & \multicolumn{2}{|c|}{$\begin{array}{l}\text { Motor } \\
\text { (leg) }\end{array}$} & \multicolumn{2}{|c|}{$\begin{array}{l}\text { Sensory } \\
\text { (pin) }\end{array}$} & \multicolumn{2}{|c|}{$\begin{array}{l}\text { Sensory } \\
\text { (touch) }\end{array}$} & \multicolumn{2}{|c|}{$\begin{array}{c}\text { Sensory } \\
\text { (proprioception) }\end{array}$} & \multicolumn{2}{|c|}{$\begin{array}{c}\text { Sensory } \\
\text { (deep pain) }\end{array}$} \\
\hline & & $R$ & $L$ & $R$ & $L$ & $R$ & $L$ & $R$ & $L$ & $R$ & $L$ & $R$ & $L$ \\
\hline 1 & $\mathrm{C} 4 / \mathrm{A}$ & -1 & +1 & 0 & -1 & 0 & 0 & -8 & -2 & 0 & 0 & -3 & 0 \\
\hline 2 & $\mathrm{C} 4 / \mathrm{A}$ & 0 & -3 & 0 & +1 & +2 & -3 & -5 & -14 & 0 & -1 & 0 & -1 \\
\hline 3 & C6/A & 0 & +2 & 0 & 0 & 0 & -5 & -7 & -5 & -1 & 0 & -2 & 0 \\
\hline 4 & $\mathrm{~T} 3 / \mathrm{A}$ & 0 & 0 & 0 & -1 & -2 & -2 & -1 & -1 & 0 & 0 & -3 & -2 \\
\hline 5 & $\mathrm{C} 4 / \mathrm{B}$ & 0 & +1 & 0 & 0 & 0 & -5 & +2 & +1 & +3 & +2 & +1 & +1 \\
\hline 6 & $\mathrm{C} 5 / \mathrm{B}$ & +1 & +1 & 0 & 0 & +10 & +13 & -2 & -5 & +5 & 0 & +2 & -3 \\
\hline 7 & $\mathrm{C} 5 / \mathrm{B}$ & -1 & -2 & 0 & 0 & +2 & +1 & -2 & -2 & 0 & +1 & 0 & 0 \\
\hline 8 & $\mathrm{C} 5 / \mathrm{B}$ & -6 & -3 & 0 & 0 & -17 & -11 & -3 & 0 & +5 & +1 & +1 & +2 \\
\hline 9 & $\mathrm{~T} 1 / \mathrm{B}$ & +1 & +1 & 0 & 0 & 0 & -1 & -23 & -22 & 0 & 0 & 0 & +1 \\
\hline 10 & T8/B & 0 & 0 & 0 & 0 & -6 & -3 & -7 & -1 & -3 & -1 & 0 & 0 \\
\hline 11 & $\mathrm{C} 4 / \mathrm{C}$ & 0 & +1 & -1 & +2 & 11 & -10 & -2 & -18 & 0 & -1 & -1 & -4 \\
\hline Total & & -6 & -1 & -1 & +1 & 0 & -26 & -56 & -69 & +9 & +1 & -5 & -6 \\
\hline \multicolumn{14}{|c|}{ Non-operated patients } \\
\hline 1 & C6/A & 0 & 0 & 0 & 0 & 0 & -3 & +2 & +4 & +1 & 0 & 0 & +1 \\
\hline 2 & $\mathrm{C} 4 / \mathrm{B}$ & 0 & +1 & 0 & 0 & 0 & 0 & -4 & -7 & +5 & +4 & 0 & +3 \\
\hline 3 & $\mathrm{C} 5 / \mathrm{B}$ & -1 & +1 & 0 & 0 & +9 & +3 & -8 & +3 & 0 & 0 & -2 & 0 \\
\hline 4 & $\mathrm{C} 5 / \mathrm{B}$ & 0 & 0 & 0 & 0 & +2 & -8 & -10 & -3 & +3 & -2 & +1 & 0 \\
\hline 5 & C6/B & -2 & 0 & 0 & 0 & -2 & -1 & +4 & -4 & 0 & 0 & -5 & -5 \\
\hline 6 & C6/B & 0 & 0 & 0 & 0 & +2 & +6 & -2 & +3 & +2 & 0 & 0 & 0 \\
\hline 7 & $\mathrm{C} 3 / \mathrm{C}$ & -1 & 0 & +2 & -3 & -6 & -3 & -2 & -2 & -4 & -5 & 0 & 0 \\
\hline 8 & $\mathrm{C} 5 / \mathrm{C}$ & +1 & 0 & 0 & -1 & -1 & +3 & +14 & +6 & 0 & 0 & +3 & +3 \\
\hline Total & & -3 & +2 & +2 & -4 & +4 & -3 & -6 & 0 & +7 & -3 & -3 & +2 \\
\hline
\end{tabular}


Table 6 Number of patients reporting changes in 8 parameters. The first 4 are compared with the neurological examination

\begin{tabular}{|c|c|c|c|c|c|c|c|c|}
\hline $\begin{array}{l}\text { Patient } \\
\text { reported } \\
\text { category }\end{array}$ & $\begin{array}{l}\text { Motor } \\
(\text { arm })^{*}\end{array}$ & $\begin{array}{l}\text { Motor } \\
(\text { leg })^{*}\end{array}$ & $\begin{array}{c}\text { Sensory } \\
(\text { pin })^{*}\end{array}$ & $\begin{array}{l}\text { Sensory } \\
\text { (touch })^{*}\end{array}$ & $\begin{array}{l}\text { Sensory } \\
\text { (temp.) }\end{array}$ & $\begin{array}{l}\text { Sensory } \\
(B \& B)^{I}\end{array}$ & $\begin{array}{l}\text { Control } \\
(B \& B)^{1}\end{array}$ & $\begin{array}{c}\text { Control } \\
\text { trunk }\end{array}$ \\
\hline Improved & $5(2)(1,2)$ & $3(1)(1)$ & $5(3)(1,1,23)$ & $4(1)(3)$ & 5 & 4 & 2 & 6 \\
\hline Worsened & $2 \quad(1)(9)$ & 1 & 0 & $1(1)(8)$ & 0 & 0 & 0 & 1 \\
\hline Unchanged & 4 & 7 & 6 & 6 & 6 & 7 & 9 & 4 \\
\hline
\end{tabular}

*For these parameters, the first number in brackets in each row indicates the number of patients for whom the reported change was verified at the last neurological examination. The second number(s) in brackets indicates the change in the score(s) for each verified patient when the last examination was compared to the first. Each side (R\&L) was considered separately but the ASIA scores shown here represent the algebraic sum of both sides. Some patients improved on one side but worsened on the other. Compare with Table 5. ${ }^{1}$ Bowel and Bladder

Table 7 Number of patients with changes in each of four parameters by self report and ASIA scores

\begin{tabular}{|c|c|c|c|c|c|c|c|c|}
\hline \multirow[b]{2}{*}{ Number } & \multicolumn{2}{|c|}{ Motor (arm) } & \multicolumn{2}{|c|}{ Motor (leg) } & \multicolumn{2}{|c|}{ Sensory (pin) } & \multicolumn{2}{|c|}{ Sensory (touch) } \\
\hline & $\begin{array}{l}\text { Patient } \\
\text { report }\end{array}$ & $\begin{array}{l}\text { ASIA } \\
\text { score }\end{array}$ & $\begin{array}{l}\text { Patient } \\
\text { report }\end{array}$ & $\begin{array}{l}\text { ASIA } \\
\text { score }\end{array}$ & $\begin{array}{l}\text { Patient } \\
\text { report }\end{array}$ & $\begin{array}{l}\text { ASIA } \\
\text { score }\end{array}$ & $\begin{array}{l}\text { Patient } \\
\text { report }\end{array}$ & $\begin{array}{l}\text { ASIA } \\
\text { score }\end{array}$ \\
\hline Improved & 5 & $6^{\mathrm{a}}$ & 3 & $2^{b}$ & 5 & $4^{c}$ & 4 & $1^{\mathrm{d}}$ \\
\hline Worsened & 2 & $4^{\mathrm{a}}$ & 1 & $3^{b}$ & 0 & $8^{c}$ & 1 & $10^{\mathrm{d}}$ \\
\hline Unchanged & 4 & 2 & 7 & 7 & 6 & 1 & 6 & 0 \\
\hline
\end{tabular}

${ }^{\mathrm{a}} 1$ showed an improvement on 1 side and a worsening on the other (Range: +1 to $+2 ;-1$ to -6 per side). ${ }^{\mathrm{b}} 1$ showed an improvement on 1 side and a worsening on the other (Range: +1 to $+2 ;-1$ per side). ${ }^{c} 2$ showed an improvement on 1 side and a worsening on the other (Range: +1 to $+11 ;-1$ to -17 per side). ${ }^{\mathrm{d}}$ (Range: +1 to $+2 ;-1$ to -23 per side)

neurological examinations for four parameters that appeared on both instruments. Only about one-quarter to one-half of reported improvements and worsenings were corroborated. Most of the eight parameters were reported by the patients as having no change. Table 7 compares the summary data of the surveys against the examination scores. Patients tended to underestimate the losses of function, particularly sensory, and when Tables 6 and 7 are compared, it is clear that improvements as well as worsenings went unrecognized in some patients. For example, in the motor arm category, five patients reported improvement but only two were verified (Table 6). Therefore, four additional $(6-2)$ patients had some slight improvement but were not aware of it (Table 7). There was no significant correlation between the patients' reports and the neurological examinations in any of the four parameters (upper extremity motor: $r=0.27$; lower extremity motor: $r=0.00$; pinprick: $r=0.35$; light touch: $r=0.37$; all $P>0.25$ ). Correlation was no better for the motor modalities than sensory ones.

\section{Neurophysiology assessment}

Cervical somatosensory evoked potentials were frequently contaminated by background EMG activity leading to variability in latency and amplitude measurements. No changes in cervical somatosensory evoked potentials were noted following any patients' surgery. No changes in lumbosacral somatosensory evoked potentials attributable to surgery were seen. No subject in the surgery group had motor evoked potentials (MEP) in lower limb muscles either before or after surgery. No consistent changes in upper limb MEP's attributable to surgery were found. BMCA of lower limbs indicated decreased spasticity in four patients in the 4-8 months after surgery extending to the twelfth month. Six patients showed change in measured spasticity of less than $15 \%$ and one subject demonstrated increased spasticity beginning at 8 months after surgery. When patient self reports of percent change in spasticity were compared by regression analysis with spasticity measured by BMCA, a significant correlation was found $(r=0.65$, $P<0.03)$.

\section{Magnetic resonance imaging ( $M R I)$}

Of 44 scheduled MRI's in 11 patients, 42 were completed. On initial MRI's spinal cord size was decreased in seven patients, normal in two and increased in two, only one of whom had a cyst. T2 signal was increased at the level of injury in 10 of 11 patients and extended from $1-5$ vertebral bodies. Six patients had small intramedullarly cysts at the level of injury.

At 4,8 and 12 months after surgery, the omentum enhanced with gadolinium in all patients and there was contact with the dorsum of the cord in nine of 11 cases. [See Figures 1, 2 and 3 for examples]. In two cases, there was evidence of compression of the cord at 4 months which decreased at 8 months. These patients 
did not change neurologically. Spinal cord size increased in six patients by 4 to 8 months after surgery without cyst enlargement, but then remained stable at 12 months. [See Figures $1 \mathrm{~A}$ and $1 \mathrm{C}$ and Figures $3 \mathrm{~A}$ and $3 \mathrm{C}$ for examples]. The $\mathrm{T} 2$ signal increased in intensity and in extent beginning at either 4 or 8 months in six of 11 patients and remained stable but definitely still increased over baseline at 12 months. [See Figures 1B, 1D, 3B and 3D for examples]. Increased spinal cord enhancement with gadolinium occurred at 4 and 8 months in three patients. Patients showed little change in spinal cord signal or shape between 8 months and 12 months.

\section{Complications}

No patient developed external CSF leakage. Three patients, however, developed persistent subcutaneous CSF accumulations 4-8 months after surgery. All required lumboperitoneal shunts 8 months after surgery for this problem. Two of these three patients also required a posterior wound revision and one developed a progressive decrease in bilateral biceps and wrist extensor function beginning at 4 months after surgery. Three of these four muscle groups in this patient had been Grade 4 preoperatively. His MRI 4 months after surgery showed omentum in contact with the spinal cord. By 6 months, both his biceps had
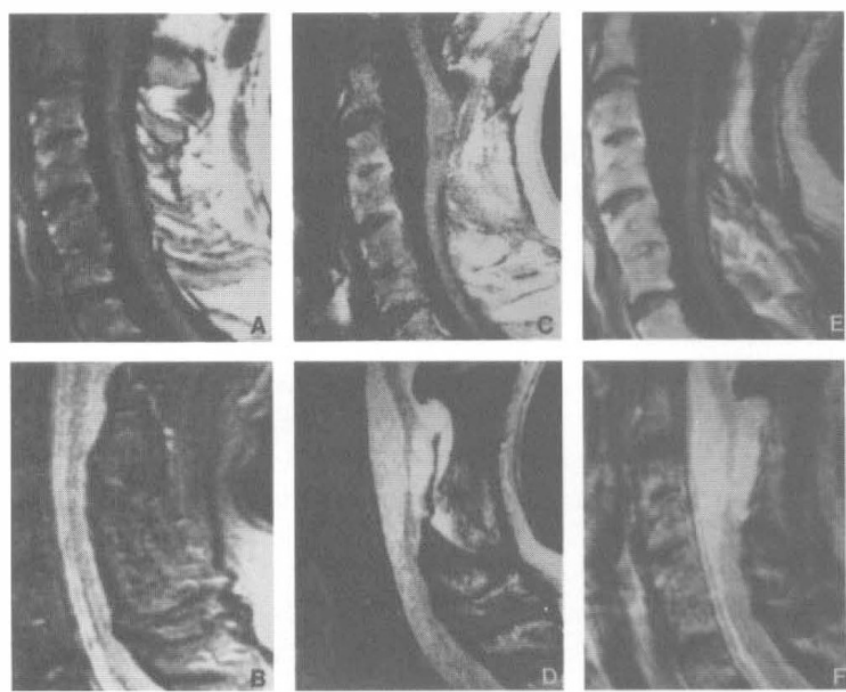

Figure 1 (A) Preoperative T1-weighted image of patient 1 showing focal area of gliosis and myelomalacia. (B) Preoperative T2-weighted image of patient 1 showing only an atrophic spinal cord. (C) One year after surgery, the spinal cord is enlarged with a central cyst on T1-weighted images. The spinal cord is pulled back into the laminectomy. (D) Fat is seen abutting the spinal cord with increased T2 signal intensity and deviation of the spinal cord posteriorly. Fat abutted the spinal cord. (E) On T1-weighted images $4 \frac{1}{2}$ years after surgery, the spinal cord is atrophic with no omentum. (F) On T2-weighted images $4 \frac{1}{2}$ years after surgery the atrophic spinal cord is seen become weaker (from Grade 4 to Grade 1) and the MRI showed definite evidence of increased graft size with spinal cord compression. The graft was removed and was not found to be anatomically connected to the cord. By 2 years postoperative, the patient's left biceps recovered to Grade 2 but the right biceps remained with only Grade 1 function. One patient required revision of a lateral abdominal wall hernia at the site where the graft was brought through the abdomen. This was done 18 months after his original procedure, and the graft as it entered the abdomen was viable with a palpable pulse.

\section{Summary}

(1) Based on neurological examinations (ASIA scores), there was no evidence of motor or sensory improvement after omental transposition in the second series despite indications of motor or sensory improvement in two patients in the pilot series;

(2) There was evidence, which approached statistical significance in the second series, of a decrease in sensory function after surgery;

(3) Gains and losses in ASIA scores in certain patients in both the operated and non-operated
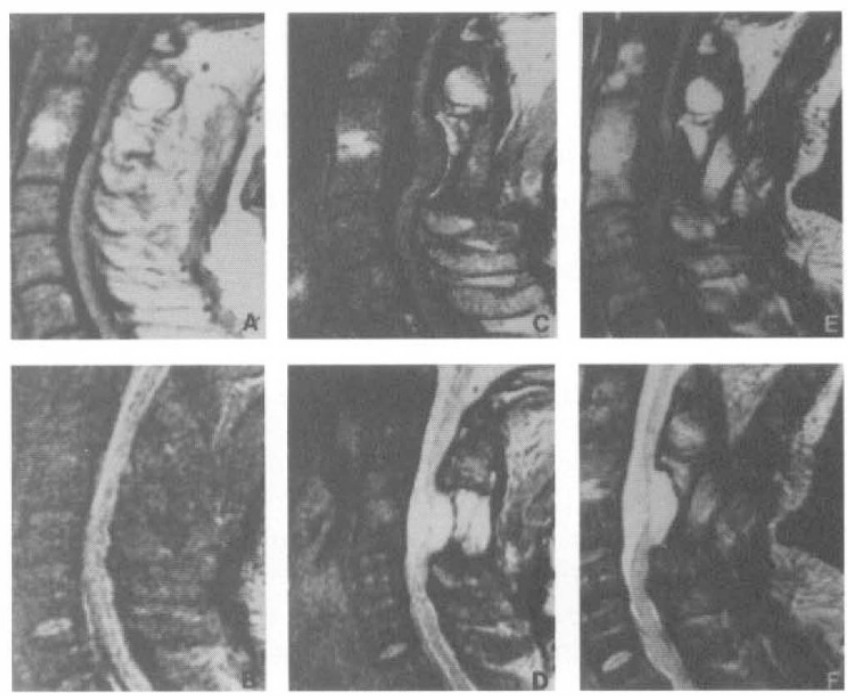

Figure 2 (A) This preoperative MRI of patient 2 shows on T1-weighted images a small area of gliosis at C3-C4 with myelomalacia. (B) On T2-weighted images, atrophic spinal cord is seen. (C) At 1 year after surgery the spinal cord is enlarged, deviated posteriorly and connected by fat on T1weighted images. (D) The spinal cord shows increased T2 signal intensity with fat abutting the spinal cord on T2weighted images. (E) On T1-weighted images at $4 \frac{1}{2}$ years after surgery the spinal cord is unchanged from the MRI, 1 year posteriorly. (F) On T2-weighted images at 4 $1 \frac{1}{2}$ years after surgery, the spinal cord is unchanged from 1 year posteriorly 

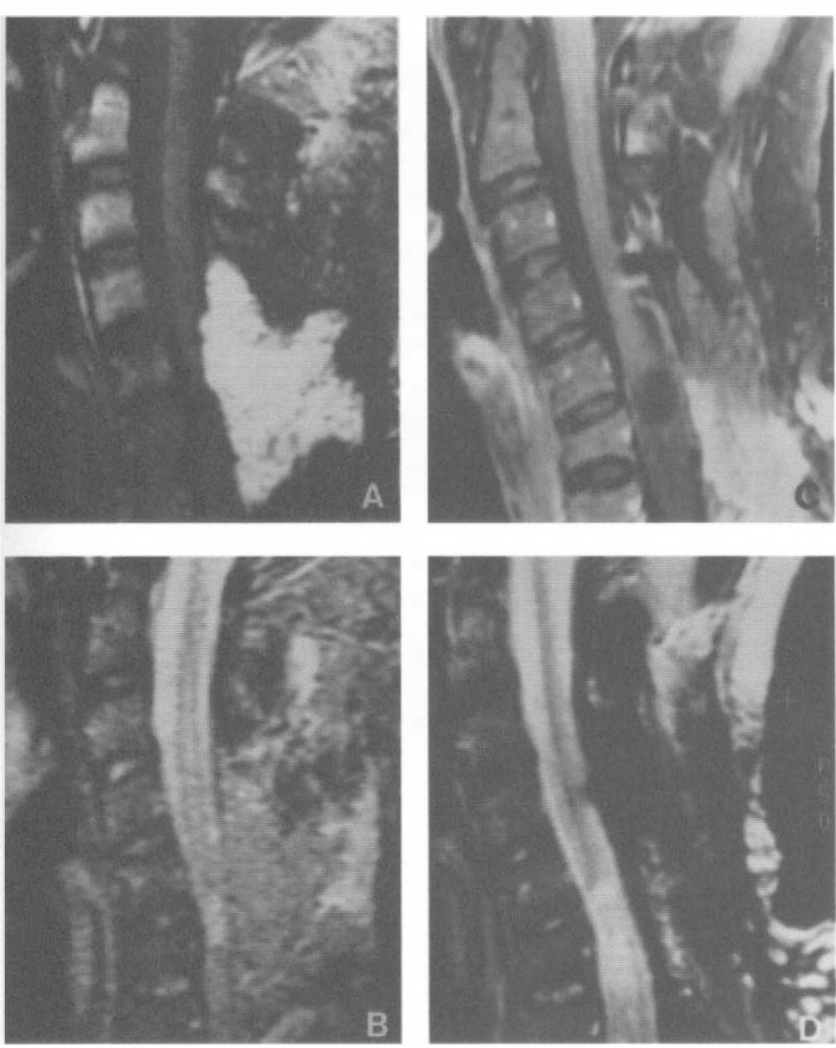

Figure 3 (A) One week postoperative MRI with T1weighted images is shown for patient 3. Fat can be seen abutting the spinal cord in the area of injury. (B) On T2weighted images at 1 week after surgery fat is seen abutting the spinal cord with increased T2 intensity in the spinal cord. (C) MRI at 1 year after surgery. On T1-weighted images the spinal cord is increased in size with fat abutting it. A cyst is seen which is also enlarged centrally. (D) Increased T2 signal intensity is seen within the spinal cord at 1 year after surgery

groups did occur, most notably a loss of motor and sensory function in one patient in the operated group;

(4) Neurological examinations could not verify patient reports of motor and sensory recovery. In fact, some improvements and losses found during examinations went unreported by the patients;

(5) Improved truncal control beginning at 4-8 months after surgery was reported to be of functional benefit in six patients, particularly in two (AIS C). This improvement could neither be verified nor disputed since this parameter was not measured objectively in either the first or second series;

(6) In the second series there was a statistically significant correlation between self reports of changes in spasticity and changes measured by BMCA of the lower limbs $(r=0.65, P<0.03)$;
(7) There were no changes in cervical or lumbosacral somatosensory evoked potentials $(n=13)$ or in upper or lower limb motor evoked potentials $(n=11)$ after surgery in any patient;

(8) At 1 year after surgery, MRI scans showed increased T2 signal intensity in eight of 13 patients, increased size of spinal cord in seven of 13, and graft enhancement by gadolinium in all patients.

\section{Discussion}

Omental transposition has been performed on approximately 40 chronically spinal cord injured patients by Goldsmith in the United States. ${ }^{1}$ At least 120 patients have been operated upon in China, Japan, Mexico, Great Britain and India. ${ }^{27-33}$ The character of published data, except for a few detailed case reports, is often in abstract or summary form which does not provide sufficient data to allow the reader to form conclusions. Nonetheless, $40 \%$ of patients were reported to have improved after surgery. ${ }^{1}$ The authors felt, if this were true, there was a need for a limited trial of the procedure employing detailed pre- and postoperative evaluations and long term follow-up, using several measurements to provide an independent analysis of the procedure's effectiveness.

The hypothesis that omental transposition might improve conduction within existing fiber tracts in the chronically injured spinal cord is worth considering. Blight and Young have shown that relatively few axons are needed for locomotion in cats. ${ }^{44,45}$ As many as $84 \%$ of motor complete spinal cord-injured patients may be neurophysiologically incomplete ${ }^{40}$ and neuropathological studies of patients with complete spinal cord injuries have shown that $78 \%$ of patients have anatomical continuity of the spinal cord. ${ }^{46}$ Demyelination of axons is commonly found after spinal cord injury and remyelination is associated with neurological and neurophysiological recovery. ${ }^{44,45,47}$ Axonal conduction can be improved in chronically injured cat spinal cords pharmacologically. ${ }^{48}$ Omentum contains a lipid-soluble angiogenic factor which enhances new vessel growth and contains high-levels of neurotransmitters. ${ }^{2-4}$ Finally, omental transposition has been reported to enhance axonal growth across a collagen bridge, and has been reported to contain a lipid-soluble factor which enhances neurite outgrowth in neuronal cell culture ${ }^{6,7}$ It is conceivable therefore that omental transposition could enhance function of existing tracts either by remyelination or by provision of deficient neurotransmitters or both.

Spontaneous late improvement in motor function (after the first 12 months) has been reported in as many as $30 \%$ of patients. ${ }^{49}$ Therefore the authors wished to study only those patients whose time since injury was well beyond this. In this series, the mean time since injury was 53 months (range $21-156$ ). Half of the patients reported subjective improvements after 
surgery. Since self report forms have not been validated, this data cannot be given the same weights as neurological testing. Few actual neurological improvements were noted. High T2 signal has been associated with both gliosis and with edema. ${ }^{50}$ Change in cord size and signal intensity could be due to tethering of the cord by omentum which could explain the changes in spasticity and the decreased sensation found.

It is important to note that the power of this small study to detect any treatment effect would depend on the magnitude of that effect. Using samples of the same size as in this study, and setting the significance level at 0.05 (one-tailed), power would be adequate to detect only a large treatment effect. For example, the power to detect a difference of 1 standard deviation in mean neurological change scores (ie, a large treatment effect) would be approximately $52 \%$. In contrast, there would only be approximately $17 \%$ power to detect an improvement of 0.05 standard deviation (ie, a moderate treatment effect). Thus, the results argue against the existence of a large treatment effect upon the ASIA scores due to omental transposition particularly in AIS A and B patients but do not rule out the possibility of a small treatment effect in either a positive or negative direction. An insufficient number of AIS C patients underwent surgery to reach a conclusion for that class.

Based on the complications encountered, the length of the operative time, the modest nature of patient reported improvements, the lack of objectively measured neurological improvement, and some evidence of sensory deterioration, we find no justification for further performance of this procedure in patients with AIS A or B status.

\section{References}

1 Goldsmith HS. Brain and spinal cord revascularization by omental transposition. Neurological Research 1994; 16: 159-162.

2 Cartier R et al. Angiogenic factor: A possible mechanism for neurovascularization produced by omental pedicles. $J$ Thorac Cardiovasc Surg 1990; 99: 264-268.

3 Goldsmith HS, Griffith AL, Catsimpoolas N. Increased vascular perfusion after administration of an omental lipid fraction. Surg Gynecol Obstet 1986; 162: 579-583.

4 McIntosh TK, Goldsmith HS. Vasoactive neurochemicals in the omentum: Implications for CNS injury. In: Goldsmith $\mathrm{H}$ (ed). The Omentum. Springer-Verlag: New York 1990, pp 75-82.

5 Williams R. Angiogenesis and the greater omentum. In: Goldsmith H (ed). The Omentum Springer-Verlag: New York 1990, pp 45-61.

6 Siek GC, Marquis JK, Goldsmith HS. Experimental studies of omentum-derived neurotrophic factors. In: Goldsmith H (ed). The Omentum. Springer-Verlag: New York 1990, pp 83-95.

7 De La Torre JC, Goldsmith HC. Collagen-omental graft in experimental spinal cord transection. Acta Neurochir 1990; 102: $152-163$.

8 Goldsmith HS, Chen WF, Duckett SW. Brain vascularization by intact omentum. Arch Surg 1973; 106: $695-698$.

9 Goldsmith HS, Duckett S, Chen WF. Spinal cord vascularization by intact omentum. Am J Surg 1975; 129: $262-265$.
10 Macmillan M, Stauffer ES. The effect of omental pedicle graft transfer on spinal microcirculation and laminectomy membrane formation. Spine 1991; 16: 176-180.

11 Azzena GB et al. Omental transposition or transplantation to the brain and superficial temporal artery: Middle cerebral artery anastomosis in preventing experimental cerebral ischemia. Acta Neurochir 1983; 68: 63-83.

12 Cucca GS et al. Effect of omental transposition to the brain on protein synthesis in experimental cerebral ischemia. Acta Neurochir 1980; 51: $253-259$.

13 DeRiu PL et al. Physiological function after middle cerebral artery occlusion in rabbits with neovascularization of the brain by transposed omentum. Neurosurgery 1980; 7: 57-67.

14 Goldsmith HS, Duckett S, Chen WF. Prevention of cerebral infarction in the dog by intact omentum. Am J Surg 1975; 130: $317-320$

15 Goldsmith HS, Duckett S, Chen WF. Prevention of cerebral infarction in the monkey by omental transposition to the brain. Stroke 1978; 9: $224-229$.

16 Pau A et al. Cerebral water and electrolytes in experimental ischemia following omental transposition to the brain. Acta Neurochir 1982; 54: 213-218.

$17 \mathrm{Pau}$ A, Sehrbundt Viale E, Turtas S. Effect of omental transposition to the brain on the cortical content of norepinephrine, dopamine, 5-hydroxytryptamine, and 5-hydroxyindoleacetic acid in experimental cerebral ischemia. Acta Neurochir 1982; 66: $159-164$

18 Miyamoto S et al. Cerebral revascularization by omental graft for moya-moya disease. In: Goldsmith $\mathrm{H}$ (ed). The Omentum. Springer-Verlag: New York 1990, pp 159-164.

19 Abraham J. Omental transposition to the brain: experimental and human applications. In: Goldsmith $\mathrm{H}$ (ed). The Omentum. Springer-Verlag: New York 1990, pp 147-157.

20 Frackowiak R, Neil-Dwyer G. Studies on cerebral blood flow and oxygen metabolism in patients with established cerebral infarct undergoing omental transposition. Stroke 1987; 18: 46-51.

21 Goldsmith HS et al. Omental transposition to brain of stroke patients. Stroke 1979; 10: 471-472.

22 Liu JF, Wang ZZ, Liu YT. Intracranial transposition of pedicled omentum in the management of ischemic cerebrovascular disease. $J$ Nerv Ment Disorders (in Chinese) 1980; 6: $321-323$.

23 Ni MS, Zou XW, Xie KM. Free omental autotransplant to brain surface in ischemic cerebrovascular disease. Chin Med J 1983; 96: $787-789$.

24 Rosadini $\mathrm{G}$ et al. An rCBF6 follow-up study in stroke patients after omentum transposition to the brain. In: Goldsmith $\mathrm{H}$ (ed). The Omentum. Springer-Verlag: New York 1990, pp 109-115.

25 Zhang C. Intracranial free omentum with microsurgical technic in the treatment of ischemic cerebrovascular disease. Chung Hua Shen Ching Ching Shen Tsa Chin 1983; 16: $23-25$.

26 Zhu ZC, Wu WL, Mo YZ. Omental transposition to the brain for cerebrovascular occlusive disease. Chung Hua Wai Ko Tsa Chih 1982; 20: $11-13$

27 Abraham $\mathrm{J}$ et al. Omento-myelo-synangiosis in the management of chronic traumatic paraplegia: câse report. Paraplegia 1980; 25: $44-49$.

28 Goldsmith HS, Neil-Dwyer MS, Barsoum FFS. Omental transposition to the chronically injured human spinal cord Paraplegia 1986; 24: $173-174$.

29 Min-Shu Z et al. Experimental and clinical use of omental transposition for spinal cord pathology. In: Goldsmith H (ed). The Omentum. Springer-Verlag: New York 1990, pp 173-186.

30 Nagashima $\mathrm{C}$ et al. Omentum transplantation to the cervical cord with microangio anastomosis. No Shinkei Geka 1991; 19(4): 309318.

31 Rafael $\mathrm{H}$ et al. Omental Transplantation in the management of chronic traumatic paraplegia. Acta Neurochir 1992; 114: $145-$ 146.

32 Song MF. Indications and complications of omental transposition to the spinal cord. Chung Hua Wai Ko Tsa Chih 1990; 28: $342-345$. 
33 Zou XW. Omental transposition in the surgical treatment of spinal cord injuries. Chin J Neurosurg 1985; 1: 107.

34 Ditunno J et al. American Spinal Injury Association: Standards for Neurologic and Functional Classification of Spinal Cord Injury. Revised 1992. Published by the American Spinal Injury Association: Chicago 1992.

35 Bracken MB et al. A randomized control trial of methylprednisolone or naloxone in treatment of acute spinal-cord injury: results of the National Acute Spinal Cord Injury Study. $N$ Engl $J$ Med 1990; 322: $1405-1411$

36 Beric A. Stability of lumbosacral somatosensory evoked potentials in a long-term follow-up. Muscle \& Nerve 1988; 11: $621-626$.

37 Sherwood AM. Characteristics of somatosensory evoked potentials recorded over the spinal cord and brain of man. IEEE Transactions on Biomedical Engineering 1981; BME-28 (7): $481-487$.

38 Dimitrijevic MR et al. Early and late lower limb motor evoked potentials elicited by transcranial magnetic motor cortex stimulation. Electroencephalogr Clin Neurophysiol 1992; 85: $365-373$.

39 Dimitrijevic MM et al. Clinical neurophysiological techniques in the assessment of spasticity. Phys Med Rehab 1989; 3(2): $64-83$.

40 Sherwood AM, Dimitrijevic MR, McKay WB. Evidence of subclinical brain influence in clinically complete spinal cord injury: discomplete SCI. J Neurol Sci 1992; 110: 90 - 98.

41 Shrout PE, Fleiss JL. Intraclass correlations: their uses in assessing rater reliability. Psych Bull 1979; 86: 420-428.
42 Sherwood AM, McKay WB, Dimitrijevic MR. Stability of multichannel surface EMG recordings for studies of motor control in upper motor neuron dysfunction. Presented at the 9th International Congress of ISEK, Florence, Italy, 28 June-2 July 1992, and published in the Abstracts, p 95.

43 Kadaba MP, Wootten ME, Gainey J, Cochran GVB. Repeatability of phasic muscle activity: performance of surface and intramuscular wire electrodes in gait analysis. J Ortho Res 1985; 3: $350-359$.

44 Blight AR, Young W. Central axons in injured cat spinal cord recover electrophysiological function following remyelination by Schwann cells. J Neurol Sci 1989; 91: 15-34.

45 Young W. Recovery mechanisms in spinal cord injury: implications for regenerative therapy. In: Seil F (ed). Frontiers of Clinical Neuroscience: Neural Regeneration and Transplantation. Alan R Liss: New York 1987, Vol 10, pp 156-159.

46 Kakulas B. The applied neurobiology of human spinal cord injury: A review. Paraplegia 1988; 26: $371-379$.

47 Waxman SG. Demyelination in spinal cord injury. Journal of Neurological Sciences 1989; 91: 1-14.

48 Blight AR, Gruner A. Augmentation by 4-aminopyridine of vestibulo spinal free-fall responses in chronic spinal-injured cats. J Neurol Sci 1989; 82: 145-159.

49 Piepmeier JM, Jenkins RN. Late neurological changes following traumatic spinal cord injury. J Neurosurg 1988; 69: 399-402.

50 Oshio I et al. Correlation between histopathologic features and magnetic resonance images of spinal cord lesions. Spine 1993; 18: $1140-1149$ 